\title{
Integration of Renewable Energies and Power Quality in the University of Seville Electrical Engineer Curricula
}

\author{
J. C. del Pino López, M. E. Méndez Treviño, J. L. Martínez Ramos, J. M. Maza Ortega, J. Riquelme Santos, J. A. Rosendo \\ Macías, A. de la Villa Jaén, M. Burgos Payán, M. Casal Gómez-Caminero, P. L. Cruz Romero and F. J. González Vázquez \\ Department of Electrical Engineering, University of Seville \\ Camino de los Descubrimientos, s/n -41092 Sevilla, Spain \\ phone: +34 54487283 - fax: +34 54487284 \\ e-mail: vaisat@esi.us.es, maru.mendez@gmail.com, camel@us.es,jmmaza@us.es, jsantos@us.es, rosendo@us.es, \\ avilla@esi.us.es,mburgos@us.es,mcasal@us.es,plcruz@us.es,gonvaz@us.es
}

\begin{abstract}
Renewable energies and power quality have increasingly become a big concern over the last decade, being preferential subjects in research, development and innovation projects world wide. University's academic programs are being adapted to this need, in order to have more qualified engineers in the future. This paper analyzes how these subjects have been integrated into the power engineer's curricula at the University of Seville.
\end{abstract}

\section{Key words.}

Renewable energy, power quality, curricula, university.

\section{Introduction}

Using renewable energy sources for producing clean and sustainable power in large quantities is now increasing interest world-wide, being stimulated by recent technological developments that have improved the costeffectiveness of the renewable resources, and also by increasing concern on the environmental impact and sustainability of fossil and nuclear fuel use. With the progress has increased recognition among professionals, politicians and the people in general that renewable energy could provide a major proportion of the world's needs by the middle of the twenty first century, that is demanding adequate investment in research and development.

On the other hand, power quality problems have increasingly become a big concern over the last decade, but surprisingly few analytical techniques have been developed to overcome these disturbances in systemequipment interactions. It is necessary that power engineers and students can find the theoretical background necessary for understanding how to analyze, predict, and mitigate power disturbances, as voltage sags or interruptions.

Due to these reasons, both renewable energies and power quality are preferential subjects in research, development and innovation projects supported by the Spanish and Andalusian government. Therefore, it is being demanded a more focus knowledge on this subjects. University's academic programs are being adapted to this need, in order to have more qualified engineers in the future.

In this paper is analyzed how these subjects have been integrated into the power engineer's curricula at the University of Seville.

\section{Academic Program Renovation}

The European Agency of the Environment (AEMA) published on the report "Energy and environment in the European Union: Tracking Progress towards Integration", an integrated strategy in energy matters that gives equal importance to the security of provision, competitiveness and environmental sustainability needed in Europe. It especially recommends the diffusion of the renewable energies. The report also demands the enlargement of the investment in investigation and development of the energy to support the commercialization and the technologies that are being designed.

On 26 August 2005 the Spanish government approved the new Renewable Energy Plan (Plan de Energías Renovables, PER). The overall aim of the new Plan is to make it possible to achieve the target of $12 \%$ of primary energy being met from renewable sources by 2010 and to do so it sets more ambitious objectives in those areas that have been developing successfully and establishes new measures to support technologies that have not yet managed to take off. In these matters, it is necessary to have the support of qualified power engineers with certain level of knowledge in theses subjects.

Previously, renewable energies and power quality were barely treated on the university's academic programs. Therefore, professional degrees and doctorate programs had to be modified, so that new professionals can be 
educated adapted to the new times. Also new investigation talents and developers of these technologies are being promoted. In order to fix these deficiencies, in the last years, subjects assigned to the Electrical Engineering Department, which is in charge to develop the electric intensification of the engineer degree, have been modified to include more contents and a better level of knowledge related with renewable energies and power quality. In Table 1 are some of these subjects, indicating which of these topics are covered in their program.

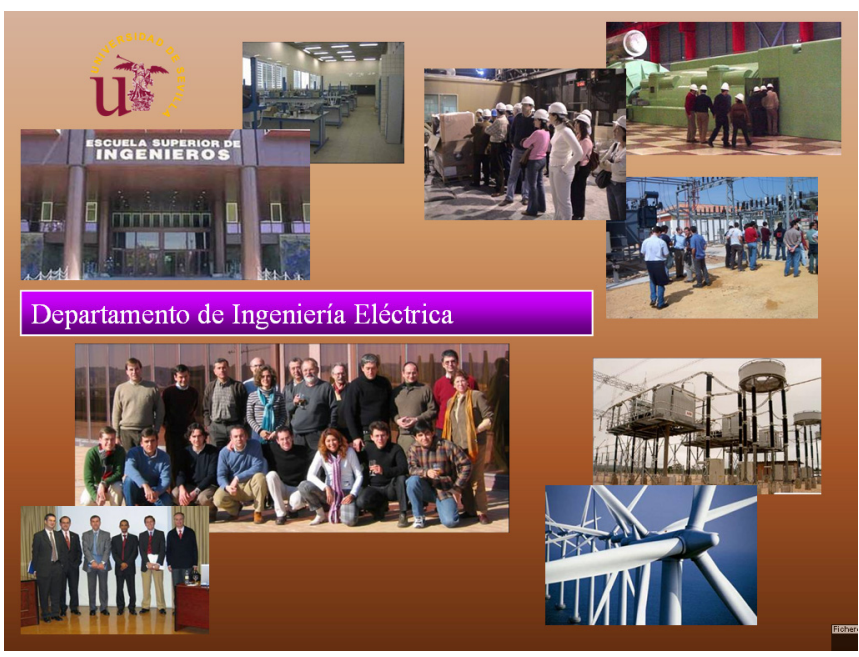

Fig. 1. Electrical Engineering Department.

Table 1. Electric intensification subjects involved in degrees integration process.

\begin{tabular}{|l|c|c|}
\hline \multicolumn{1}{|c|}{ Subject } & $\begin{array}{c}\text { Renewable } \\
\text { Energies }\end{array}$ & $\begin{array}{c}\text { Power } \\
\text { quality }\end{array}$ \\
\hline Electrical Installations $\left(4^{\text {th }}\right.$ year $)$ & $\mathrm{X}$ & $\mathrm{X}$ \\
\hline Electric Machines $\left(4^{\text {th }}\right.$ year) & $\mathrm{X}$ & $\mathrm{X}$ \\
\hline Power Electrical Plants $\left(5^{\text {th }}\right.$ year) & $\mathrm{X}$ \\
\hline $\begin{array}{l}\text { Electric Energy Management }\left(5^{\text {th }}\right. \\
\text { year) }\end{array}$ & $\mathrm{X}$ \\
\hline $\begin{array}{l}\text { Traction and Electric Drives }\left(5^{\text {th }}\right. \\
\text { year) }\end{array}$ & $\mathrm{X}$ & $\mathrm{X}$ \\
\hline Electrical Technology $\left(5^{\text {th }}\right.$ year) & $\mathrm{X}$ & $\mathrm{X}$ \\
\hline Power Electric Systems & & \\
\hline Thesis Degree &
\end{tabular}
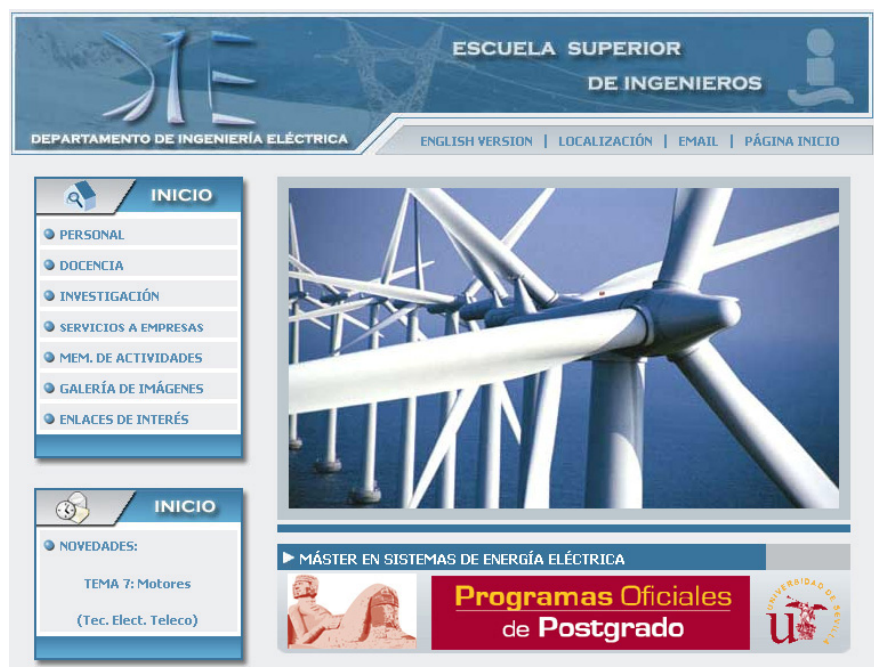

Fig. 2. Web page of the Electrical Engineering Department.
As can be seen, renewable energy and power quality are treated in almost all subjects. Examples of some of the issues related with these topics:

- Electrical Installations ( $4^{\text {th }}$ year):

This subject provides practical knowledge to the students, by presenting them the use of diverse skills related to the design of electric installations including, generating power stations, transport of the electrical energy, receiving facilities, distribution networks, regimes of neutral, distribution networks in DC, as well as the regulations and protections to assure power quality in all this.

\section{- Electric Machines (4 ${ }^{\text {th }}$ year):}

This subject provides technological knowledge and presents the use of diverse techniques related to the operation, test, control, selection, and use of the electrical machines: transformers, induction machine (double fed and squirrel-cage), synchronous machine, and DC machine. In particular there is an emphasis on the importance of the use of induction generators in the production of Aeolian energy. Also, it is study the influence of the power quality over the electrical machines in aspects like the imbalance, increase of losses and reduction of the yield.

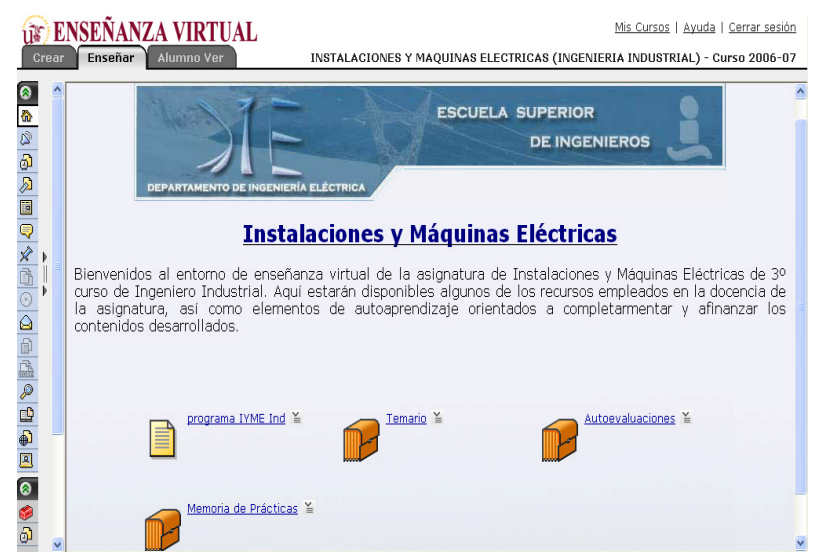

Fig. 3. On-line learning web page.

- Power Electrical plants $\left(5^{\text {th }}\right.$ year):

Here electric protections are studied, including protection systems, protection relays and associated equipment, digital protections and protections in high voltage lines, generators and transformers. Also, the electric power generation, including hydraulic, solar thermal, solar photovoltaic, wave, bioenergy and wind generation plants. As a practical example of the connection protocol to the network of electrical power stations, the connection of synchronous generators is studied from a theoretical and practical point of view, and through a laboratory practice the complete process of connection is shown.

- Electric Energy Management $\left(5^{\text {th }}\right.$ year):

Basic knowledge of the electrical energy management is provided. On one hand, there is the technical point of view approach of saving power in the industry 
through the application of power audits. On the other hand, the structure of tariffs and the hiring possibilities of electrical provision are analyzed in order to choose the hiring possibility that is more economic, given a certain profile of consumption. Finally, there is a review of the power quality importance, not only from the point of view of the interruption itself, but also from the quality of the tension wave it has within the liberalized structure of the sector. In order to help understand some of these aspects, several practical exercises are carried out in real facilities as much as in the laboratory, like for example the analysis of the quality of wave by means of a power quality analyzer.

- Traction and Electric Operations ( $5^{\text {th }}$ year):

Technological knowledge of diverse techniques related with the operation and selection of the machines and the electrical drives is provide. In particular, the specific objectives for the students of the first fourth month period consist on getting to know the operation basis of the different schemes of control, which are used in D.C. drives, as well as the basis for the selection of the converter A.C/D.C. or D.C./A.C. more adapted for each application.

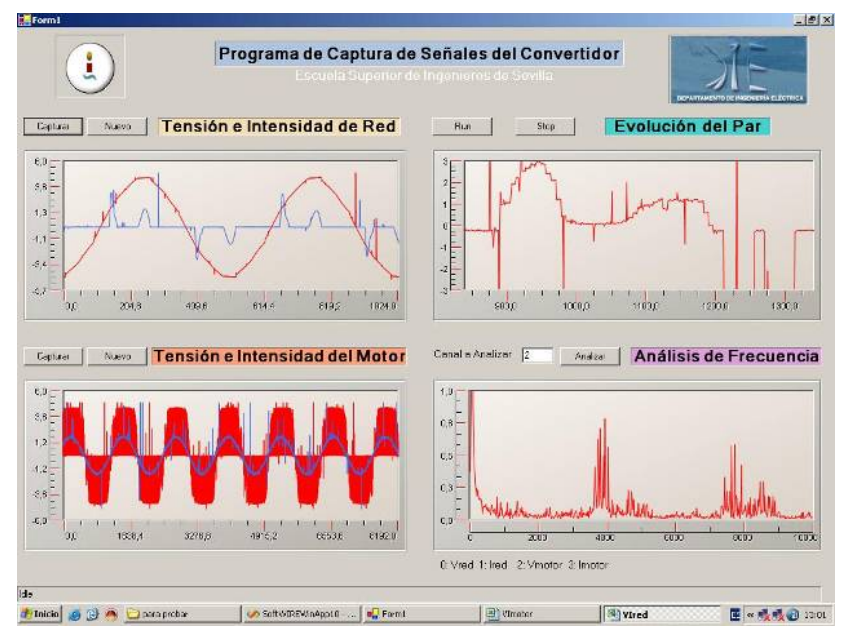

Fig. 4. Software of acquisition and analysis of waveforms.

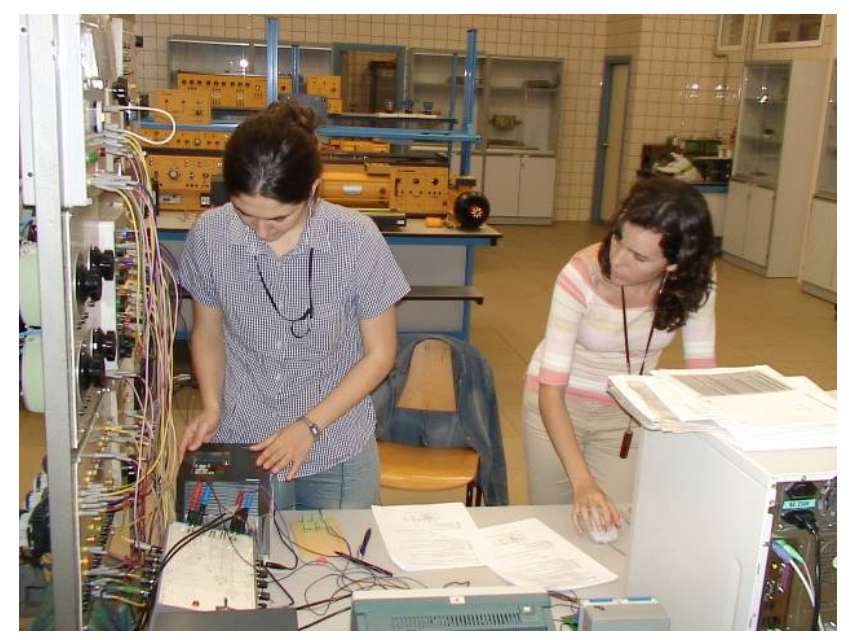

Fig. 5. Students programming the converter and analyzing waveforms.
Those of the second fourth month period are the student domination of the scalar and vector control of the induction motors, and getting to know the basic guides to select the A.C. converter more adapted for each type of application. Students learn about power quality problems through laboratory practices where they study the induction motor drive by means of a commercial converter AC, observing the influence of this type of equipment in the network (injection of overtones, etc.)

\section{- Electrical Technology $\left(5^{\text {th }}\right.$ year $)$ :}

This subject provides basic and general knowledge of the constitution, components and way of operation of the electrical systems. The concept of power quality is introduced, as well as the hydroelectric power stations, wind power stations, and the solar photovoltaic thermoelectrial generation. The program fundamentally approaches medium and high tension electric systems, constituting therefore a complement to the subject of Facilities and Electrical Machines in which the low tension was studied. Practical exercises are made in order to strengthen some of the introduced concepts. There is also an emphasis on the economic study by analyzing the economic yield that would turn out from replacing the conventional transformers currently used on solar orchards by others of higher performance. In this way, the losses would be reduced increasing at the same time the injected energy to the network. Moreover, it would have a beneficial effect in the efficiency of the global installation including the connection to the distribution network.

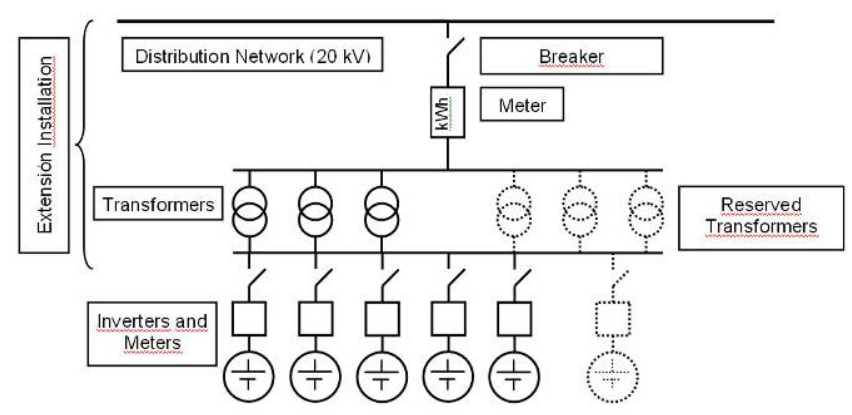

Fig. 6. Solar orchard diagram.

- Power Electric Systems $\left(5^{\text {th }}\right)$ :

The objective here is that the students obtain knowledge to be applied in the area of electrical power engineering as a whole, and diverse techniques of common use in control centres of the electric network transport. Distributed generation and network reliability are introduced. When studying the generation there is an especial emphasis in the importance that is having the generation of renewable origin, specially the Aeolian, as opposed to the conventional generation. This is motivating that the dynamic studies of the electric networks have every time greater importance. From the point of view of the market and its abrogation, every time stands out the greater importance of the generation in special regime. Also, there is a visit to the control center of ENDESA. 
All these subjects are supported by laboratory demonstrations as mentioned before, but also there are programmed visits to industrial installations.

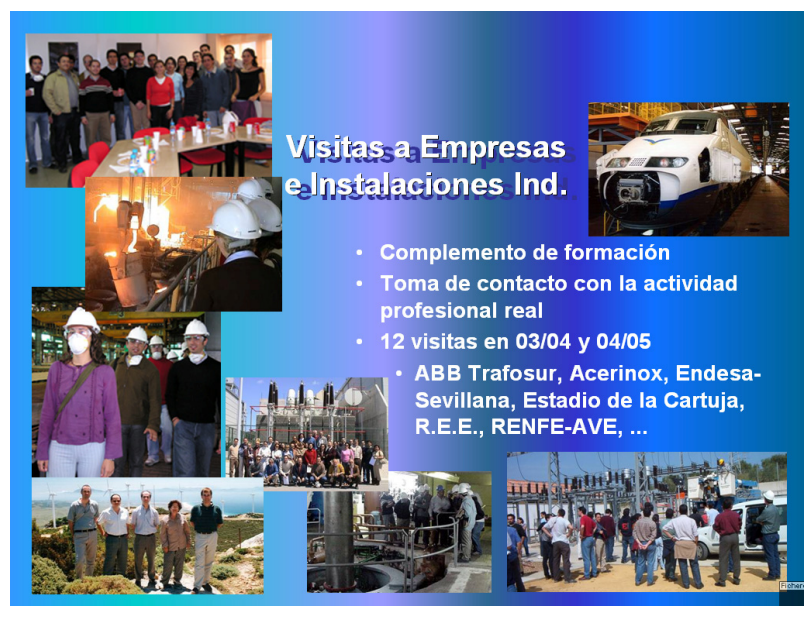

Fig. 7. Visits to industrial installations.

Thesis Degree related with renewable energies are Developed, as for example, design and construction in laboratories of a small-scale network (in low voltage) to develop theoretical and experimental studies about the impact of integration of wind power plants in the electric system transport and distribution networks. Finally, students have also the possibility to collaborate with related organizations to develop their Thesis Degree.

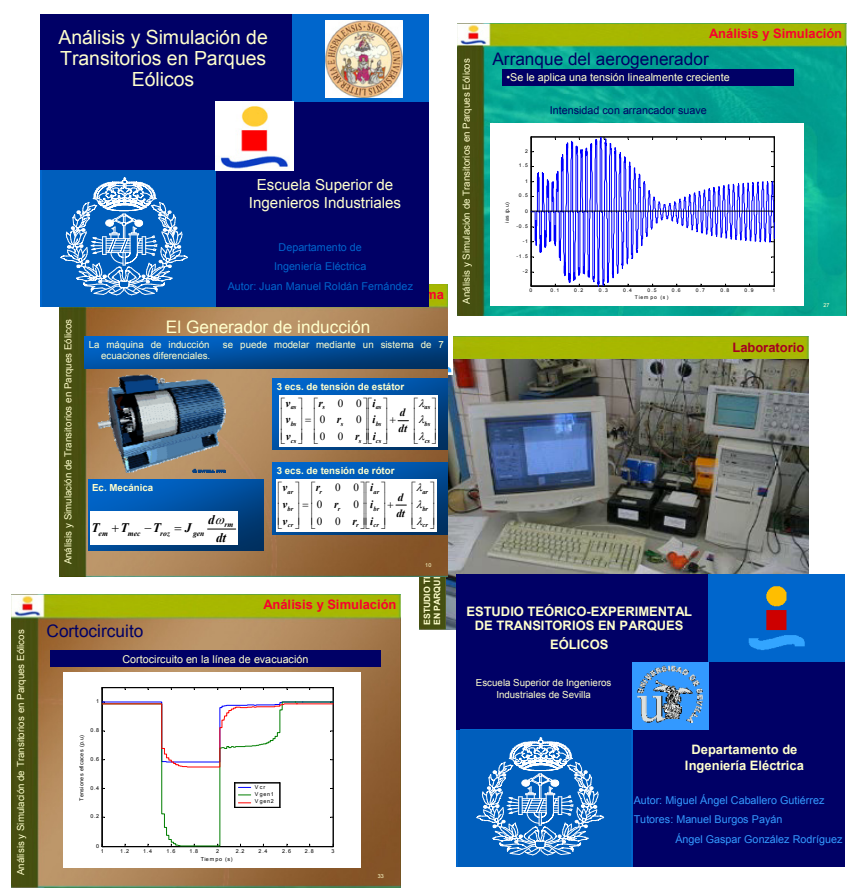

Fig. 7. Thesis degree related with wind power plants.

In order to form better professionals and researchers, the doctorate has been reinforced and converted in a new Official Master in Electric Energy Systems. Some of the subjects involved have been also renewed, focusing its programs in more specific contents related with these fields. In Table 2 are some of these subjects, indicating which of these fields are covered in their program.

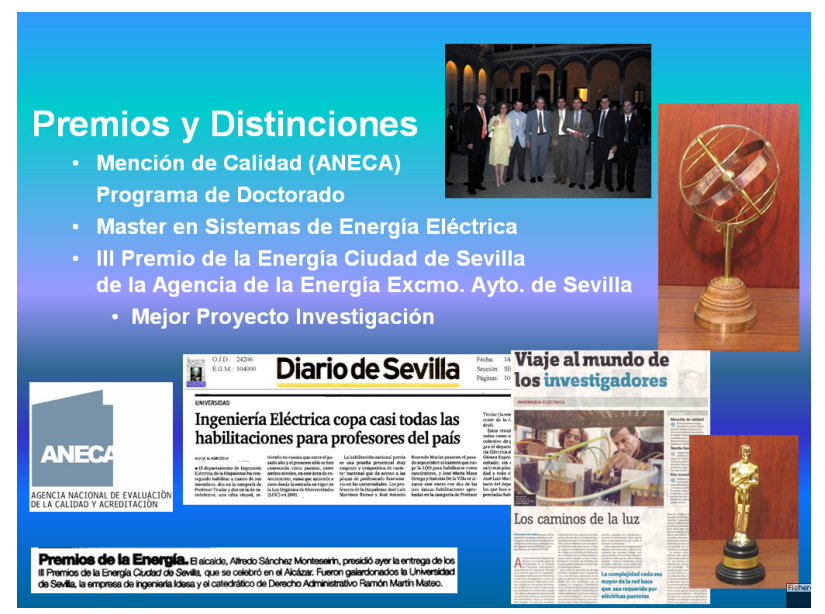

Fig. 9. Department Awards.

Table 2. Master in Electric Energy Systems subjects involved in the integration process.

\begin{tabular}{|l|c|c|}
\hline \multicolumn{1}{|c|}{ Subject } & $\begin{array}{c}\text { Renewable } \\
\text { Energies }\end{array}$ & $\begin{array}{c}\text { Power } \\
\text { quality }\end{array}$ \\
\hline $\begin{array}{l}\text { Introduction to Renewable } \\
\text { Energies in Electric Power } \\
\text { Systems }\end{array}$ & $\mathrm{X}$ & \\
\hline Management of Electric Energy & & $\mathrm{X}$ \\
\hline $\begin{array}{l}\text { Advanced Measure and } \\
\text { Protection Systems of Electric } \\
\text { Systems }\end{array}$ & & $\mathrm{X}$ \\
\hline $\begin{array}{l}\text { Optimal Operation of Electric } \\
\text { Energy Supply }\end{array}$ & $\mathrm{X}$ & $\mathrm{X}$ \\
\hline $\begin{array}{l}\text { Improvement of Power Quality } \\
\text { by Electronic Equipment }\end{array}$ & $\mathrm{X}$ \\
\hline $\begin{array}{l}\text { Advanced Analysis Techniques } \\
\text { and Electric Machine Control: }\end{array}$ & $\mathrm{X}$ & $\mathrm{X}$ \\
\hline Master Thesis &
\end{tabular}

Examples of some of the issues developed in these subjects are:

- Introduction to Renewable Energies in Electric Power Systems:

The electrical advantage of the renewable energies, due to its special and peculiar characteristics of availability and use, raises a series of problems very different from the ones that can appear in the conventional electrical power stations. The specific knowledge that this subject tries to comprise is the following: the generic characteristics of the different renewable power plants; main components of the generation facilities that use different renewable sources, mainly minihydraulic, wind and photovoltaic; the volume of energy contributed of these renewable sources; the impact of the power stations based on renewable power plants on the electric networks; the situation of the renewable energies in the generation context in Spain, the rest of Europe and at world-wide level. Some of these aspects are analyzed with the help of practical experiences in laboratory, like the comparison of the simplicity of connection to the network of asynchronous generators with respect to the synchronous ones, emphasizing its advantages and disadvantages in the influence on the network (elevated levels of intensity and greater consumption of reactive). 
- Management of Electric Energy:

This course provides basic knowledge about the power management within the electrical sector. The student is introduced to the phenomena of liberalization recently happened within the electrical sectors of diverse countries, with special attention to the Spanish case, and the form in which this one is regulated. An analysis is made on all the consequences that this radical change in the sector structure has in the different scopes of the power management: power hiring, power quality, power saving, efficient heat generation and electricity, etc. An important part of this course is getting to know the influence that the power quality has in a liberalized sector and the different phenomena that affect the same : power quality continuity and wave quality.

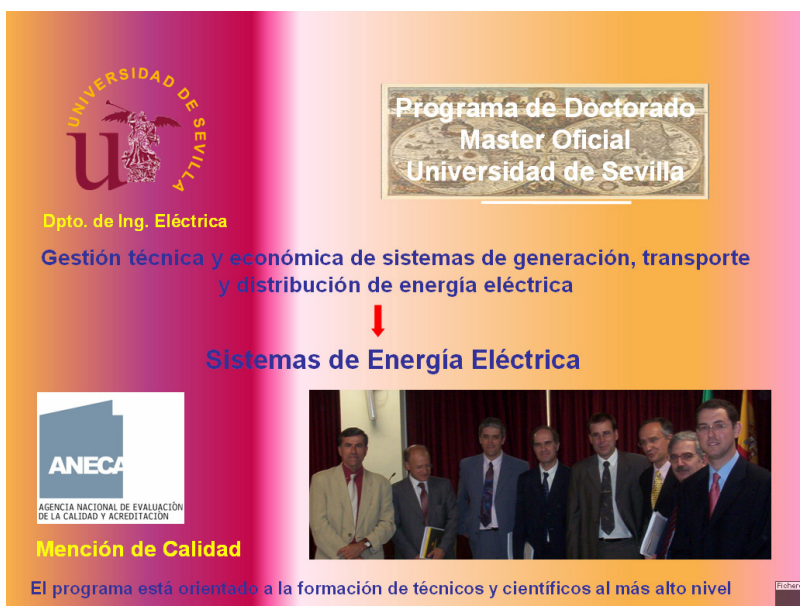

Fig. 10. Master in Electric Energy Systems.

- Advanced Measure and Protection Systems of Electric Systems:

The use of advance measure and protection systems to ensure power quality is studied with a double purpose. On one hand, the student acquires the necessary knowledge for the understanding and the design of advanced systems of measurement and protection of electrical systems, making special emphasis in the digital character that systems have been acquiring as this technology has developed. On the other hand, basic tools for the investigation in Electrical Engineering are introduced such as Matlab and PSCAD programs.

- Improvement of Power Quality by Electronic Equipment:

This subject provides basic knowledge about power quality: Different types of disturbances that affect the power quality and the causes that produce them; quantify the effect that the different types of disturbances have on the most frequent receivers in industrial electrical systems, residential and commercial; distinguish which is the more suitable mitigation measurement for each one of the studied disturbances; the topological configurations more common in technologies FACTS (Flexible AC Transmission Systems) and D-FACTS (Distributed Flexible AC Transmission Systems); the different algorithms of calculation used in FACTS and DFACTS with different purposes: references calculation, current pursuit, tension control of continuous; the models of each analyzed device FACTS and D-FACTS to be able to make simulations; the different norms or international guides related to the power quality.

- Advanced Analysis Techniques and Electric Machine Control:

The ample and progressive implantation of the electrical drives in the industry and the possibilities of automatization, control, and improvement of the productive processes efficiency, constitute the basic incentives of the investigation line. The study of the transitory processes that take place in the electrical drives- understood as a complete system including from the driven machine to the electric network connection point - is essential since the efforts to which the kinematics chain of mechanical transmission can be expose, and the disturbances that can be introduced in the electric network can be very superior to the foreseeable ones with the models based on the permanent regime. This subject is orientated to the electrical analysis of the operation and control of the machines and drives, insisting on the techniques of modelled and simulation. All this affecting the power Quality. Change of variables are used in the analysis of $\mathrm{AC}$ machines, to determinate time-varying inductances. Change of variables are also employed in the analysis of various static, constant-parameter power system components.

\section{- Optimal Operation of Electric Energy Supply}

The purpose of this course is to provide applied knowledge in the operation on the field of the electrical power systems, with special emphasis in the planning and optimal operation of the generation resources. The operations of power stations based on renewable power plants are also review in this course.

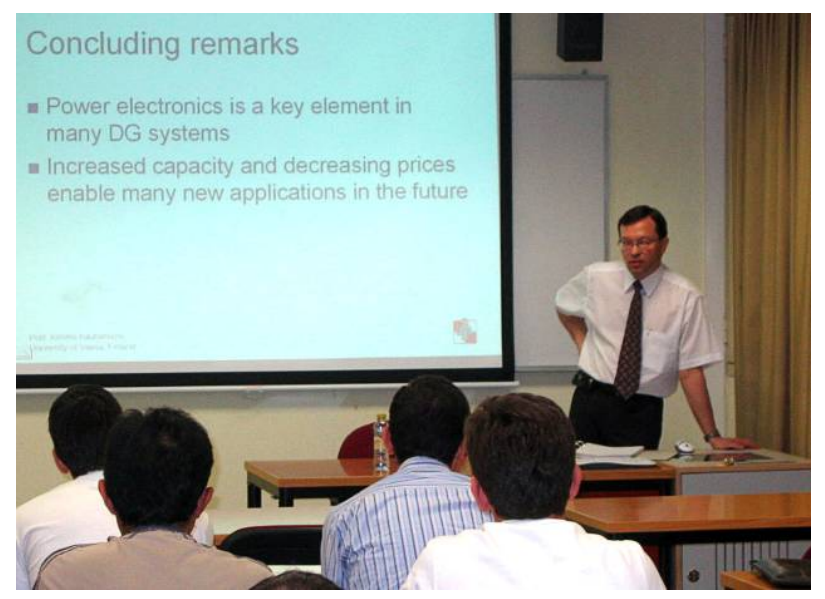

Fig. 11. Seminary given by Professor Kimmo Kauhaniemi.

In order to give students a better sight of some of the problems related with these issues, several seminars and courses are also organized, participating professionals and some known prestige researchers, as Professor Göran 
Andersson from Swiss Federal Institute of Technology, Professor Valdimiro Miranda from INESC (Portugal),

Professor Arindam Gosh from Indian Institute of Technology in Kanpur, Professor Francisco Galiana from Department of Electrical and Computer Engineering of McGill University in Montreal (Canada), Professor Claudio Cañizares from the University of Waterloo in Ontario (Canada), Professor Daniel Van Dommelen from Kath. University of Leuven (Belgium) and Professor Kimmo Kauhaniemi from the Department of Electrical Engineering in the University of Vaasa (Finland).

Students can also prepare their Master Thesis in contribution with organizations and businesses of the sector by research and development projects.

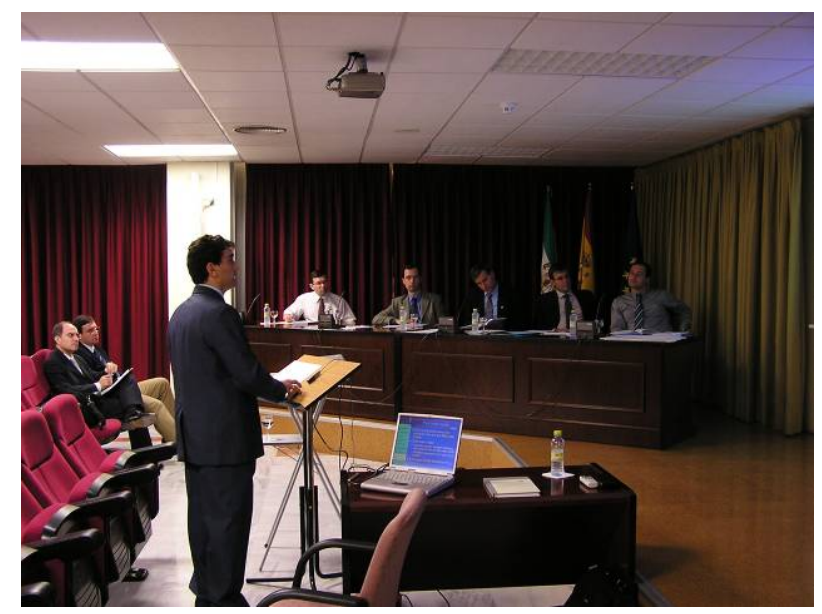

Fig. 12. Doctorate Thesis.

\section{Conclusion}

Qualified Professionals on renewable energies and power quality technologies are being highly required. Therefore, university of Seville is taking measures by adapting its curricula to include a higher focus on the concepts of renewable energy and power quality, also by encouraging investigation and development in these areas.

The future in the University is the European Higher Education Area, which main objective is the transformation of education and training throughout Europe, in order to improve the quality and effectiveness of EU education and training systems. In this sense, the School of Engineers at the University of Seville has given the first step by integrating contents in some of the subjects given in the program degree, and migrating from doctorate courses to the new official Master in Electric Energy Systems. This master has been adapted to form electric specialized engineers that will adapt to these new challenges.

\section{References}

[1] G. Boyle, "Renewable Energy. Power for a Sustainable Future", Oxford University Press.

[2] R. C. Dugan, M. F. McGranghan, H. W. Beaty, "Electrical Power Systems Quality", McGraw-Hill.
[3] Norma UNE-EN 50160:2001, “Características de la tensión suministrada por las redes generales de distribución".

[4] White Book on Renewable Energies, European Commission. 